Int. J. Electrochem. Sci., 16 (2021) Article ID: 210733

International Journal of

ELECTROCHEMICAL

SCIENCE

www.electrochemsci.org

\title{
Robust Visible-Light Photocatalytic Norfloxacin Degradation from Aqueous Solution Using Ni-doped ZnO/ MWCNTs Nanocomposite
}

\author{
Shiwei Wen ${ }^{1, *}$, Mi Chen ${ }^{2}$ and Hui Cao ${ }^{3}$ \\ ${ }^{1}$ Zhongshanhaohui metal products co., ltd, Zhongshan 528400, China \\ ${ }^{2}$ School of Management, University of Electronic Science and Technology of China, Zhongshan \\ Institute, Zhongshan 528400, China \\ ${ }^{3}$ Library, Zhongshan shaxi science \& engineering school, Zhongshan 528400, China \\ *E-mail:wenshiwei2021@ sina.com
}

doi: $10.20964 / 2021.07 .63$

Received: 9 April 2021/ Accepted: 17 May 2021 / Published: 31 May 2021

This study revealed the preparation of Ni-doped ZnO/ MWCNTs nanocomposite as a photocatalyst for degradation of norfloxacin as quinolone under UV and visible light irradiations. The chemical synthesis method was used for functionalization of MWCNTs to prepare Ni-doped ZnO/MWCNTs nanocomposite. SEM and XRD analyses of the nanocomposite revealed that it was composed of Nidoped $\mathrm{ZnO}$ spherical nanoparticles attached to a tangled network of MWCNTs. EIS and CV studies revealed that Ni-doped $\mathrm{ZnO} / \mathrm{MWCNTs}$ composites had improved interfacial charge transfer efficiency. Optical studies revealed that the band gap energy for Ni-doped ZnO/MWCNTs nanocomposites was $2.90 \mathrm{eV}$, and anchoring $\mathrm{Ni}$ into the MWCNTs and $\mathrm{ZnO}$ lattices resulted in a narrowing of the nanocomposite band gap. The photocatalytic studies revealed that after 30,60, 120, and 160 minutes of visible irradiation, respectively, and 40, 70, 150, and 200 minutes of UV irradiation, respectively, complete degradation of 10, 20,50, and $100 \mathrm{mg} / \mathrm{l}$ of norfloxacin was obtained. Results indicated that the synergetic effect of functionalized MWCNTs and Ni NPs in anocomposite caused the band gap to narrow and could provide higher redox abilities under visible light irradiation and enhance the range of a sensitization process due to form facile electron transfer and the heterojunction formation.

Keywords: Photocatalyst; Quinolones; Norfloxacin; MWCNT; ZnO; Nanocomposite; Electrochemical impedance spectroscopy

\section{FULL TEXT}

(C) 2021 The Authors. Published by ESG (www.electrochemsci.org). This article is an open access article distributed under the terms and conditions of the Creative Commons Attribution license (http://creativecommons.org/licenses/by/4.0/). 